\title{
(6) OPEN ACCESS \\ Influenza vaccine as a coronary intervention for prevention of myocardial infarction
}

\author{
C Raina Maclntyre, ${ }^{1,2}$ Abela Mahimbo, ${ }^{1}$ Aye M Moa, ${ }^{1}$ Michelle Barnes ${ }^{1}$
}

${ }^{1}$ School of Public Health and Community Medicine, University of New South Wales, Sydney, Australia

${ }^{2}$ College of Public Service \& Community Solutions, Arizona State University, Phoenix, Arizona, USA

\section{Correspondence to} Professor C Raina Maclntyre, School of Public Health and Community Medicine, Faculty of Medicine, University of New South Wales, Sydney 2052, Australia;

r.macintyre@unsw.edu.au

Received 11 May 2016 Revised 23 August 2016 Accepted 30 August 2016 Published Online First 29 September 2016

\section{(1) crossiatk}

To cite: Maclntyre $C R$, Mahimbo A, Moa AM, et al. Heart 2016;102:19531956.

\section{ABSTRACT}

Cardiovascular disease (CVD) is the leading cause of morbidity and mortality globally. Influenza is one of the leading infectious causes of morbidity and mortality globally, and evidence is accumulating that it can precipitate acute myocardial infarction (AMI). This is thought to be due to a range of factors including inflammatory release of cytokines, disruption of atherosclerotic plaques and thrombogenesis, which may acutely occlude a coronary artery. There is a large body of observational and clinical trial evidence that shows that influenza vaccine protects against AMI. Estimates of the efficacy of influenza vaccine in preventing AMI range from $15 \%$ to $45 \%$. This is a similar range of efficacy compared with the accepted routine coronary prevention measures such as smoking cessation (32-43\%), statins (19-30\%) and antihypertensive therapy (17-25\%). Influenza vaccine should be considered as an integral part of CVD management and prevention. While it is recommended in many guidelines for patients with CVD, rates of vaccination in risk groups aged $<65$ years are very low, in the range of $30 \%$. The incorporation of vaccination into routine CVD prevention in patient care requires a clinical practice paradigm change.

In 2008, cardiovascular disease (CVD) overtook communicable diseases for the first time to become the leading cause of mortality in the world, now causing approximately $13 \%$ of all deaths globally. ${ }^{1}$ Given the high global burden of coronary heart disease (CHD), prevention through identifying and mitigating risk factors is a priority. Cigarette smoking, elevated serum cholesterol levels and high blood pressure are major risk factors for developing $\mathrm{CHD}$ and significant predictors of death, and are therefore accepted targets for preventive strategies. ${ }^{2}$ When considering attributable deaths, raised blood pressure is categorised as the leading risk factor followed by tobacco use while high serum cholesterol is ranked sixth. ${ }^{3}$ Behavioural interventions such as smoking cessation, dietary and lifestyle changes, use of statins and antihypertensive drugs are accepted public health strategies for reducing the burden of CHD. ${ }^{4}$ Could influenza vaccine be an additional strategy to reduce CHD burden?

\section{INFLUENZA AS A TRIGGER FOR ACUTE MYOCARDIAL INFARCTION}

While many infections have been studied for their role in triggering vascular events, the most consistent evidence is for influenza. ${ }^{5}$ There is compelling evidence for the association between influenza infection and acute myocardial infarction (AMI). There is a peak of both influenza and cardiac deaths in winter. ${ }^{5} 6$ Influenza epidemics are associated with increased hospitalisation rates for AMI and other cardiovascular-related conditions. ${ }^{78}$ A number of studies have shown a strong association between influenza and AMI. ${ }^{5} 9-11$ There is a wealth of retrospective and prospective ${ }^{5}$ studies showing a temporal relationship, with influenza respiratory illnesses preceding AMI by a variable time, with the strongest association occurring in the first three days, but lasting up to 1 year. ${ }^{12}$

Atherosclerosis is an inflammatory response culminating in a plaque comprised of a core rich in lipids, pro-inflammatory cells and cytokines, and a fibrous cap. It is thought that influenza acts by many mechanisms, including inflammatory release of cytokines that causes a pro-thrombotic state, local disruption of coronary plaques, as well as physiological effects such as hypoxia and tachycardia, to cause acute obstruction of coronary arteries that may be otherwise subcritically stenosed. ${ }^{13}$ Other mechanisms include sympathetic activation with subsequent effects on vascular tone with vasoconstriction; thrombogenesis through the nonspecific pro-coagulant and thrombophilic effects of inflammation; epithelial dysfunction; and inadequate coronary artery blood flow through increased metabolic demand with fever and tachycardia, reduced oxygen saturation and hypotension with secondary vasoconstriction. ${ }^{14}$ Further, influenza has been shown to produce direct effects on the heart. Histopathological and molecular studies on influenza-infected mice have shown that the virus can be isolated from heart tissue and that its presence leads to local inflammatory changes. ${ }^{15}$ The multiple mechanisms by which influenza may precipitate AMI are shown in figure 1.

\section{INFLUENZA VACCINE FOR SECONDARY CORONARY PREVENTION}

Evidence is accumulating about the effectiveness of influenza vaccination in coronary disease prevention. Observational studies have shown the protective effectiveness of influenza vaccine against $\mathrm{AMI}$ is between $19 \%$ and $45 \% .{ }^{9} 1617$ A meta-analysis of case-control studies showed that influenza vaccine has a summary vaccine effectiveness of $29 \%$ against AMI. ${ }^{18}$ In a meta-analysis of randomised controlled trials (RCTs), influenza vaccine was protective against the outcome of AMI but the pooled estimate was not statistically significant (relative risk (RR) $0.85,95 \%$ CI 0.44 to 1.64$){ }^{5}$ However, each RCT showed efficacy of influenza vaccine against composite coronary morbidity and mortality outcomes. ${ }^{19} 20$ Another RCT found that influenza vaccine reduced major cardiovascular events by $10 \%$ in patients with acute coronary syndromes during a 12-month follow-up period. ${ }^{21}$ 
Figure 1 Mechanisms by which influenza infection may precipitate acute myocardial infarction.

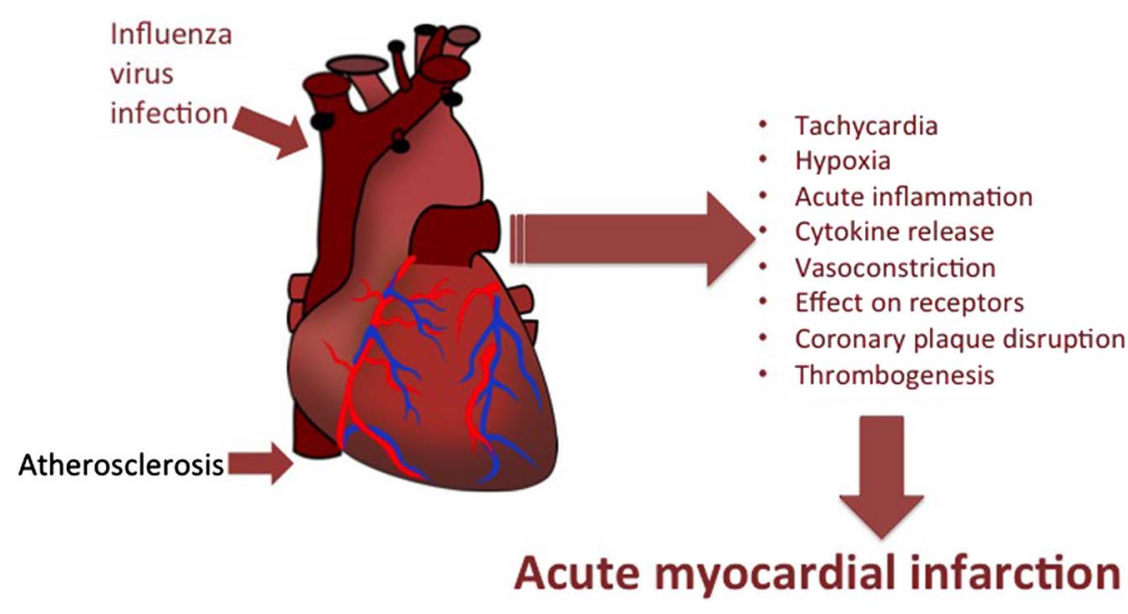

If influenza vaccine protects against AMI, the mechanism is through preventing influenza, thereby preventing the possibility of AMI triggered by the mechanisms discussed above. An additional putative molecular mechanism for the protective effect of vaccination is that vaccine-induced antibody cross-reacts with a human bradykinin receptor. ${ }^{22}$ It is postulated that this interaction could lead to increased levels of nitric oxide, which increases the efficiency of myocardial oxygen use, as well as leading to increased blood flow through vasodilation and possible angiogenesis.

\section{SMOKING CESSATION FOR SECONDARY PREVENTION}

A significant body of evidence exists supporting that smoking cessation is effective in the secondary prevention of AMI and reduces AMI mortality rates. ${ }^{43-25}$ The OASIS 5 study revealed that adherence to smoking cessation interventions among recent quitters within 6 months of an index AMI was associated with a $43 \%$ RR reduction for recurrent myocardial infarction. ${ }^{4}$ The survival and ventricular enlargement (SAVE) trial found that smoking cessation among people who had left ventricular systolic dysfunction secondary to AMI was associated with a $32 \%$ reduction in risk of death/recurrent myocardial infarction during a median follow-up period of 42 months. ${ }^{26}$ Pooled estimates from one systematic review revealed that people with established CHD who quit smoking had a $32 \%$ and $36 \%$ risk reduction in nonfatal myocardial infarction and all-cause mortality, respectively. ${ }^{24}$

\section{ANTIHYPERTENSIVE MEDICATION FOR SECONDARY PREVENTION}

Individual RCTs have established the efficacy of antihypertensive medications in secondary prevention of AMI to be approximately $20-25 \%$ despite the differences in the study populations in terms of presence or absence of left ventricular dysfunction or heart failure. $^{26-29}$ In addition, a systematic review focusing on specific antihypertensive agents showed that the use of long-term $\beta$-blockers reduces the risk of reinfarction by approximately $25 \% .^{30}$ In their meta-analysis, Pepine et $a l^{31}$ demonstrated that verapamil reduced the incidence of non-fatal reinfarction by $21 \%$ among patients with CVDs. In patients with preserved left ventricular function, ACE inhibitors have been shown to be effective in the secondary prevention of both fatal and non-fatal myocardial infarction by $17.3 \% .^{32}$ The role of calcium antagonists in secondary prevention has been controversial, with some studies showing calcium antagonists to be more harmful than beneficial, particularly in increasing the risk of AMI among hypertensive patients. ${ }^{33}$ It has been argued however that individual calcium antagonists should be taken into consideration while analysing their efficacy. ${ }^{31}$

\section{STATINS FOR SECONDARY PREVENTION}

Several studies have investigated the impact of statins in the secondary prevention of coronary heart diseases. RCTs involving patients from a range of age groups, different cholesterol levels, $\mathrm{C}$ reactive protein levels with/without a history of angina or previous myocardial infarction have revealed statin efficacy ranging from $19 \%$ to $30 \% .^{35-37}$

Afilalo et $a l^{38}$ conducted a meta-analysis that showed that statins reduced the risk of reinfarction by $26 \%$. These findings are similar to other meta-analyses done by Cholesterol Treatment Trialists Collaborators, Sheng et al and Gould et al, ${ }^{39-41}$ who reported 23\%, 28\% and 29.5\% RR reduction of myocardial infarction, respectively. When comparing the efficacy of statins by gender, the overall risk reduction of major coronary events was found to be similar among men and women (approximately 30\%). ${ }^{42}$ When assessing the efficacy of intensive (high dose) versus less intensive statin therapies (low dose), a meta-analysis of RCTs established that more intensive statin therapy was associated with a further $17 \%$ RR reduction of myocardial infarction compared with the latter. ${ }^{43}$

\section{DOES INFLUENZA VACCINE HAVE A PLACE IN ROUTINE CORONARY PREVENTION?}

Despite the large body of evidence supporting a role for influenza vaccine in coronary prevention, rates of influenza vaccination in patients with heart diseases are low, ${ }^{44}$ and vaccination is not a priority among physicians. A significant proportion of healthcare budgets is spent on the acute treatment of AMI and the long-term management of CHD. Costs per year of life saved range from US $\$ 4350$ for smoking cessation programmes to US $\$ 142-760$ for statin use in under 65 year olds. ${ }^{45} 46$ Further gains in prevention of CHD would therefore likely be costeffective, especially if using a low-cost strategy such as influenza vaccination. Influenza vaccination is a relatively cheap, safe and evidence-based public health measure that is underused in at-risk populations currently. Influenza vaccination has been shown to be cost-effective in preventing influenza-like illnesses and hospitalisation for pneumonia and influenza, without any consideration of its efficacy in the prevention of AMI. ${ }^{47}$ It is therefore likely that influenza vaccine could be highly costeffective in the prevention of AMI particularly for high-risk 
Table 1 Efficacy of accepted coronary interventions and influenza vaccine in the prevention of myocardial infarction

\begin{tabular}{lll}
\hline Coronary intervention & Prevention & $\begin{array}{l}\text { Intervention } \\
\text { efficacy/effectiveness } \\
\text { against acute } \\
\text { myocardial infarction (\%) }\end{array}$ \\
\hline Smoking cessation ${ }^{423-25}$ & Secondary & $32-43$ \\
Statins $^{38}$ & Secondary & $19-30$ \\
Antihypertensive drugs $^{26-29} 32$ & Secondary & $17-25$ \\
Influenza vaccine $^{5918}$ & Secondary & $15-45$ \\
\hline
\end{tabular}

people. Table 1 summarises the range of efficacy of accepted coronary interventions compared with influenza vaccination and highlights the potential gains of including vaccination in routine prevention of CHD.

A well-powered RCT of influenza vaccine in AMI prevention would add to the available evidence. ${ }^{48}$ However, there is already compelling evidence that influenza vaccine should be considered as an integral part of CHD management and prevention. While it is recommended in many guidelines for patients with coronary artery disease, rates of vaccination in risk groups aged $<65$ years are low. ${ }^{49}$ In addition, this recommendation is seen as one that aims to prevent influenza, rather than to reduce the risk of AMI. A paradigm change may be required to encourage clinicians to see influenza vaccine as a cheap, safe and effective additional prevention strategy for patients with CHD.

Contributors CRM: conceived study idea, wrote and revised the manuscript. AM: conducting literature review and drafting of manuscript. AMM: contributed to revision and submission of manuscript. MB: contributed to drafting of manuscript.

Competing interests CRM has received in-kind support and funding for investigator-driven research from GlaxoSmithKline, Pfizer, Merck and bioCSL, and has sat on advisory boards for Merck, GlaxoSmithKline and Pfizer.

Provenance and peer review Not commissioned; externally peer reviewed.

Open Access This is an Open Access article distributed in accordance with the Creative Commons Attribution Non Commercial (CC BY-NC 4.0) license, which permits others to distribute, remix, adapt, build upon this work non-commercially, and license their derivative works on different terms, provided the original work is properly cited and the use is non-commercial. See: http://creativecommons.org/ licenses/by-nc/4.0/

\section{REFERENCES}

1 World Health Organization (WHO). Cardiovascular diseases (CVDs). http://www. who.int/mediacentre/factsheets/fs317/en/ (accessed 4 Apr 2016).

2 Kannel WB. Hypertension, blood lipids, and cigarette smoking as co-risk factors for coronary heart disease. Ann N Y Acad Sci 1978;304:128-39.

3 World Health Organization (WHO). Global status report on noncommunicable diseases 2010. Description of the global burden of NCDs, their risk factors and determinants. 2011. http://www.who.int/nmh/publications/ncd_report_chapter1. pdf ?ua=1 (accessed Jan 2015).

4 Chow CK, Jolly S, Rao-Melacini P, et al. Association of diet, exercise, and smoking modification with risk of early cardiovascular events after acute coronary syndromes. Circulation 2010;121:750-8.

5 Warren-Gash C, Smeeth L, Hayward AC. Influenza as a trigger for acute myocardial infarction or death from cardiovascular disease: a systematic review. Lancet Infect Dis 2009:9:601-10.

6 Collins SD. Excess mortality from causes other than influenza and pneumonia during influenza epidemics. Public Health Reports (1896-1970) 1932;47:2159-79.

7 Madjid M, Miller CC, Zarubaev VV, et al. Influenza epidemics and acute respiratory disease activity are associated with a surge in autopsy-confirmed coronary heart disease death: results from 8 years of autopsies in 34,892 subjects. Eur Heart J 2007;28:1205-10.

8 Yap FH, Ho PL, Lam KF, et al. Excess hospital admissions for pneumonia, chronic obstructive pulmonary disease, and heart failure during influenza seasons in Hong Kong. J Med Virol 2004;73:617-23.

9 Maclntyre $C R$, Heywood $A E$, Kovoor $P$, et al. Ischaemic heart disease, influenza and influenza vaccination: a prospective case control study. Heart 2013;99:1843-8.
10 Clayton T, Capps NE, Stephens NG, et al. Recent respiratory infection and the risk of myocardial infarction. Heart 2005;91:1601-2.

11 Guan X, Yang W, Sun X, et al. Association of influenza virus infection and inflammatory cytokines with acute myocardial infarction. Inflammation Res 2012;61:591-8

12 Meier CR, Jick SS, Derby LE, et al. Acute respiratory-tract infections and risk of first-time acute myocardial infarction. Lancet 1998;351:1467-71.

13 Corrales-Medina VF, Suh KN, Rose G, et al. Cardiac complications in patients with community-acquired pneumonia: a systematic review and meta-analysis of observational studies. PLoS Med 2011;8:e1001048.

14 Corrales-Medina VF, Madjid M, Musher DM. Role of acute infection in triggering acute coronary syndromes. Lancet Infect Dis 2010;10:83-92.

15 Fislova T, Gocnik M, Sladkova T, et al. Multiorgan distribution of human influenza A virus strains observed in a mouse model. Arch Virol 2009;154:409-19.

16 Hsu SY, Chen FL, Liaw YP, et al. A matched influenza vaccine strain was effective in reducing the risk of acute myocardial infarction in elderly persons: a population-based study. Medicine (Baltimore) 2016;95:e2869.

17 Siriwardena AN, Gwini SM, Coupland CAC. Influenza vaccination, pneumococcal vaccination and risk of acute myocardial infarction: matched case-control study. CMAJ 2010;182:1617-23.

18 Barnes $M$, Heywood AE, Mahimbo $A$, et al. Acute myocardial infarction and influenza: a meta-analysis of case-control studies. Heart 2015;101:1738-47.

19 Ciszewski A, Bilinska ZT, Brydak LB, et al. Influenza vaccination in secondary prevention from coronary ischaemic events in coronary artery disease: FLUCAD study. Eur Heart J 2008;29:1350-8.

20 Gurfinkel EP, Leon de la Fuente R, Mendiz O, et al. Flu vaccination in acute coronary syndromes and planned percutaneous coronary interventions (FLUVACS) Study. Eur Heart J 2004;25:25-31.

21 Phrommintikul A, Kuanprasert S, Wongcharoen W, et al. Influenza vaccination reduces cardiovascular events in patients with acute coronary syndrome. Eur Heart $J$ 2011;32:1730-5.

22 Veljkovic V, Glisic S, Veljkovic N, et al. Influenza vaccine as prevention for cardiovascular diseases: possible molecular mechanism. Vaccine 2014;32:6569-75.

23 Shah AM, Pfeffer MA, Hartley LH, et al. Risk of all-cause mortality, recurrent myocardial infarction, and heart failure hospitalization associated with smoking status following myocardial infarction with left ventricular dysfunction. Am J Cardiol 2010;106:911-16.

24 Critchley J, Capewell S. Smoking cessation for the secondary prevention of coronary heart disease. Cochrane Database Syst Rev 2003;(4):CD003041.

25 World Health Organization (WHO). Prevention of Cardiovascular Disease Guidelines for assessment and management of cardiovascular risk. 2007. http://www.who.int/ cardiovascular_diseases/guidelines/Full\%20text.pdf (accessed Jan 2016).

26 Pfeffer MA, Braunwald E, Moyé LA, et al. Effect of captopril on mortality and morbidity in patients with left ventricular dysfunction after myocardial infarction: results of the Survival and Ventricular Enlargement Trial. N Engl J Med 1992;327:669-77.

27 Yusuf S, Pepine CJ, Garces C, et al. Effect of enalapril on myocardial infarction and unstable angina in patients with low ejection fractions. Lancet 1992;340:1173-8.

28 Yusuf S, Sleight P, Pogue J, et al. Effects of an angiotensin-converting-enzyme inhibitor, ramipril, on cardiovascular events in high-risk patients. The Heart Outcomes Prevention Evaluation Study Investigators. N Engl J Med 2000;342:145-53.

29 Ferrari R, Bertrand ME, Remme WJ, et al. Insight into ACE inhibition in the prevention of cardiac events in stable coronary artery disease: the EUROPA trial. Expert Rev Cardiovasc Ther 2007;5:1037-46.

30 Yusuf S, Peto R, Lewis J, et al. Beta blockade during and after myocardial infarction: an overview of the randomized trials. Prog Cardiovasc Dis 1985:27:335-71

31 Pepine CJ, Faich G, Makuch R. Verapamil use in patients with cardiovascular disease: an overview of randomized trials. Clin Cardiol 1998;21:633-41.

32 Saha SA, Molnar J, Arora RR. Tissue ACE inhibitors for secondary prevention of cardiovascular disease in patients with preserved left ventricular function: a pooled meta-analysis of randomized placebo-controlled trials. J Cardiovasc Pharmacol Ther 2007;12:192-204.

33 Held PH, Yusuf S. Effects of $\beta$-blockers and calcium channel blockers in acute myocardial infarction. Eur Heart J 1993;14(Suppl F):18-25.

34 Yusuf S, Held P, Furberg C. Update of effects of calcium antagonists in myocardia infarction or angina in light of the second Danish Verapamil Infarction Trial (DAVIT-II) and other recent studies. Am J Cardiol 1991;67:1295-7.

35 Tonkin A, Aylward P, Colquhoun D, et al. Prevention of cardiovascular events and death with pravastatin in patients with coronary heart disease and a broad range of initial cholesterol levels. N Engl J Med 1998;339:1349-57.

36 Scandinavian Simvastatin Survival Study Group. Randomised trial of cholesterol lowering in 4444 patients with coronary heart disease: the Scandinavian Simvastatin Survival Study (4S). Lancet 1994;344:1383-9.

37 Sacks FM, Pfeffer MA, Moye LA, et al. The effect of pravastatin on coronary events after myocardial infarction in patients with average cholesterol levels. 
Cholesterol and Recurrent Events Trial investigators. N Engl J Med 1996:335:1001-9.

38 Afilalo J, Duque G, Steele R, et al. Statins for secondary prevention in elderly patients: a hierarchical bayesian meta-analysis. J Am Coll Cardiol 2008; $51: 37-45$.

39 Baigent C, Blackwell L, Emberson J, et al., Cholesterol Treatment Trialists' (CTT) Collaboration. Efficacy and safety of more intensive lowering of LDL cholesterol: a meta-analysis of data from 170,000 participants in 26 randomised trials. Lancet 2010;376:1670-81.

40 Sheng X, Wei L, Murphy MJ, et al. Statins and total (not LDL) cholesterol concentration and outcome of myocardial infarction: results from a meta-analysis and an observational study. Eur J Clin Pharmacol 2009;65:1071-80.

41 Gould AL, Davies GM, Alemao E, et al. Cholesterol reduction yields clinical benefits: meta-analysis including recent trials. Clin Ther 2007;29:778-94.

42 LaRosa JC, He J, Vupputuri S. Effect of statins on risk of coronary disease: a meta-analysis of randomized controlled trials. JAMA 1999;282:2340-6.

43 Josan K, Majumdar SR, McAlister FA. The efficacy and safety of intensive statin therapy: a meta-analysis of randomized trials. CMAJ 2008;178:576-84.
44 Madjid M, Alfred A, Sahai A, et al. Factors contributing to suboptimal vaccination against influenza: results of a nationwide telephone survey of persons with cardiovascular disease. Tex Heart Inst I 2009;36:546.

45 Ladapo JA, Jaffer FA, Weinstein MC, et al. Projected cost-effectiveness of smoking cessation interventions in patients hospitalized with myocardial infarction. Arch Intern Med 2011;171:39-45.

46 Tonkin AM, Eckermann S, White $\mathrm{H}$, et al. Cost-effectiveness of cholesterol-lowering therapy with pravastatin in patients with previous acute coronary syndromes aged 65 to 74 years compared with younger patients: results from the LIPID study. Am Heart J 2006;151:1305-12.

47 Newall AT, Scuffham PA, Kelly $H$, et al. The cost-effectiveness of a universal influenza vaccination program for adults aged $50-64$ years in Australia. Vaccine 2008;26:2142-53.

48 MacIntyre RC, Heywood AE, Kovoor P. Influenza virus vaccine reduces risk of ischemic events: time for a large-scale randomized trial? Future Cardiol 2014;10:35-7.

49 AlHW. Australian Institute of Health and Welfare 2011. 2009 Adult Vaccination Survey: summary results. Cat. no. PHE 135. Canberra. http://www.aihw.gov.au/ publication-detail/?id=10737418409 (accessed Apr 2016). 